El Departamento de Educación Industrial por su misma naturaleza necesita de este tipo del apoyo para erradicar de una vez por todas el futuro profesional de tiza y tablero y convertirlo potencialmente en un generador de ideas transformadas en hechos.

\title{
LA ENSEÑANZA DE LA QUIMICA
}

La Investigación en Docencia de la Química se ha introducido en la formación del futuro docente como una componente indispensable en la estructuración de un pensamiento creador e investigador.

\section{Objetivos}

Adquirir las técnicas generales de investigación.

Desarrollar un diseño de investigaciones.

\section{Metodología}

-Un grupo de 263 estudiantes escoge un profesor del Departamento quien ejerce las funciones de orientador del trabajo.

-El grupo presenta un anteproyecto al orientador quien hace los ajustes del caso.

-El proyecto, aprobado por el orientador, es presentado por éste, al grupo pedagógico del Departamento.

-El desarrollo del proyecto está a cargo del grupo de estudiantes. En reuniones periódicas con el orientador se hace un control y evaluación permanente.

- Terminado el trabajo, los estudiantes presentan un informe escrito al Departamento y desarrollan un Seminario para información a la comunidad Universitaria.

Este trabajo de Investigación es obligatorio para los estudiantes de la modalidad principal y opcional para los de otras modalidades.

Además de esta investigación realizada en el departamento de Química, se han incluido los siguientes trabajos.

Diseño y experimentación de la unidad "equilibrio químico" por el método de la enseñanza programada; Módulos educativos. Ensayo; Diagnóstico previo sobre la enseñanza de la química en ocho colegios de Bogotá; Modelo de teoría estructural para la enseñanza de la química orgánica en bachillerato; Educación personalizada: instrucción en base a unidades didácticas y en base a módulos. Su eficiencia; Desarrollo de un sonoviso sobre soluciones. Prueba preliminar sobre su eficiencia en el aprendizaje y la química en el bachillerato: de motivación o de conceptos.

Se tienen proyectados los siguientes trabajos:

Dotación de laboratorios y su utilización en la enseñanza de la química en los colegios del D.E. de Bogotá; diagnóstico sobre la enseñanza de la química en el Distrito Especial 
de Bogotá; Bases para escribir un texto guía para el primer nivel de química para el bachillerato; Matrices de objetivos: Recursos didácticos empleados en la enseñanza de la química en la región de Sogamoso-Boyacá y función, dotación y mantenimiento del laboratorio de química de los colegios departamentales de Cundinamarca. 